\title{
It never rains in VR
}

Where two worlds collide.

\section{John Gilbey}

Jim and I are a pretty good double act. He's the modeller and I'm the data wrangler I don't criticize his code and he doesn't mess up my data. Except that we both do, then we argue, then we get drunk, then it's OK. Like last night.

Slouched on the sofa in Theatre 2 this morning, Jim looked even worse than me. This was a lecture theatre back when students actually came here in person. Now it's a virtual reality studio - not the biggest, not the smartest, but it does us very nicely. You see, it saves us having to go out to work.

We got in early on the climatechange ticket, when the University of Rural England was still just a college. Whole-landscape studies, that's our thing. Soil, hydrology, microdimate, plant ecology, you name it. Fifty thousand autonomous data loggers spread across the river basin, all pootling away $24 / 7$ and mesh networked back to the Data Centre.

The really great thing is that it all feeds into the VR system. The whole valley, mapped out in glorious 256-bit colour, photorealistic, surround sound - with the data streamed in real time, or selected highlights, or fast-forward, whatever. So you get to do all your fieldwork from the comfort of a sofa - a real one, you don't mess with things like that - without having to go outside. And it never rains, so everyone's happy.

\section{Except the Prof.}

She stamped in just as we got settled. We were in trouble - big time. The model was showing some weird nutrient-flux events that didn't fit the standard profile. Now usually, when things go wrong, Jim and I spot it first and, you know, improve reality a bit. Sadly, our biggest sponsor had seen this one first. The one that pays for all our toys. Oops.

It seems that our data grid now links directly into the government eco-policy engine, so big profile changes have an immediate impact on the national subsidy structure. Nice of her to tell us.

There was the usual 'inside out' feeling as the system came up, then one of the lasers failed to sync. Pulses of purple light don't improve hangovers. Finally, plink, there we were, flying our sofa a thousand
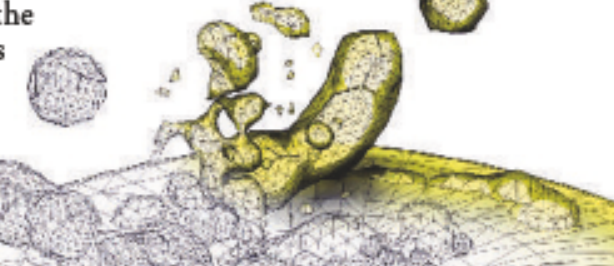

${ }^{\alpha}$ You won't melt $\succeq$ - GO?"

So, two hours later, there we were. Looking at the real hill: steep, and smelling strongly of sheep. We stumbled halfway up before Jim's knees went and he collapsed, groaning, on to the grass next to a sensor endosure. I checked the probe. Automatic diagnostics, selfcalibrating, sealed for life: nothing to go wrong. Crazy.

"Afternoon." Looking up, I saw the farmer walking down the hill. He nodded towards Jim. "Not as pretty as the last one." I explained that Jenny was now back in the States, then made some gentle enquiries.

No, he hadn't been spraying slurry. Anyway, all the tractors have loggers, so we'd know, wouldn't we? No, there wasn't a secret underground reservoir and definitely no Roman aqueduct. He paused to adjust his cap.

“Just checking your probe fences," he volunteered, "like it says

in the agreement. We starts at the top and we work downhill."

We? I glanced uphill and saw his colfeet above the English countryside. With unnecessary zeal, the Prof zoomed us up the valley to the edge of the moor, dumping us with an inertia-free crash on a convenient rock outcrop. I closed my eyes until the nausea passed.

She spoke to thin air. "Are you there, Jenny?"

A small cartoon rabbit wearing glasses and a T-shirt hopped out from behind a gorse bush. The T-shirt said 'sysadmin' on the front, in pink neon. "Hi folks, want to see the playback?"

Jenny's avatar flipped through some clips showing, on dry summer days, waves of ground water rolling down the hill opposite, like slow liquid avalanches. Glowing numbers and isohyets chased gleefully across the landscape. The system modelled tongues of dissolved nutrients moving at more than two kilometres an hour.

"Can't be happening," I said defiantly, "must be the model."

Jim swore. "Sensor fault - has to be." I pointed out that a dozen devices couldn't all be reading wrong. The Prof steamed. "Just go out there and sort it - now!"

"But it might rain," wailed Jim. league. An old, arthritic sheepdog was gamely stumping towards us, tongue lolling. He was making about two kilometres an hour. Pausing beside the fence he raised one hind leg and, with a look of satisfaction, anointed the sensor with concentrated nutrients.

"Old age," said the farmer. ${ }^{\alpha} \mathrm{He}$ has to stop at every one nowadays."

I called Jenny. "Tell the Prof we are witnessing an event. She should be able to see it in the model, sort of." Jenny expressed qualified delight. "She's watching it now - do we need to refine the model?" she asked.

"Only if Vet Science have got some code for a collie with prostate trouble..."

Jenny relayed the information. There were strange rending sounds in the background. "The Prof is biting chunks out of the sofa. I think she's practising for when you get back. Anything else you need me for?"

I pondered this for a moment. “Jenny, when did you last test the fire sprinklers in the VR Theatre?"

John Gilbey is a writer living in the vir tual reality of West Wales. The views expressed are his own, and he is welcome to them. 